\title{
Cardiopulmonary exercise testing in improving the rehabilitation of patients with heart failure and anemia Case report
}

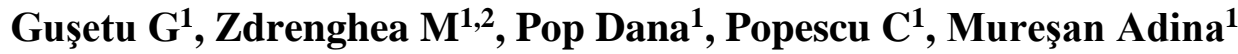 \\ I"Iuliu Hatieganu" University of Medicine and Pharmacy Cluj-Napoca \\ ${ }_{2}^{2}$, Ion Chiricuţă " Oncology Institute Cluj-Napoca
}

\author{
corresponding author: Zdrenghea Mihnea - m.zdrenghea@yahoo.com \\ Cluj-Napoca Oncology Institute - Hematology Department, B-dul 22 Decembrie nr. 73, Cluj- Napoca \\ 400124, Romania. tel. 0040741100480
}

Anemia is known to be recurrent in heart failure patients and its presence is an unfavorable prognostic factor $(1,2)$. However, treatment with iron supplements or erythropoietin has proven to improve the health of this category of patients $(1,3)$.

Except in cases when hemoglobin value is below $8 \mathrm{~g} \%$, anemia does not exclude patients with ischemic cardiomyopathy and/or heart failure from rehabilitation programs, but patients with anemia have lower exercise capacity and significantly lower VO2 peak increase than patients without anemia $(4,5)$. Anemia associated with sedentary lifestyle complicates the situation, since they both decrease exercise capacity, and makes the choice of rehabilitation programs and exercise intensity more difficult, chiefly in patients with left ventricular systolic dysfunction, which has a considerable impact on the beneficial effects of physical activity $(2,6,7)$.

Patient GN, 73 years of age, with antecedent ventricular extrasystoles and high blood pressure, diabetes, and conservatively treated inferior (2008-clinically silent) and anterior myocardial infarction (octomber 2010); afterwards interventional revascularization (post infarction angina) namely triple aorto-coronary by-pass grafting was performed in April 2011 (internal mammary-left anterior descending artery, vein graft to the diagonal artery, to the posterior interventricular artery, in-stent restenosis) but several months later the patients showed signs of systolic heart failure with enlarged heart on echocardiogram, lack of apical aneurysm and $25 \%$ ejection fraction. Taking into account the presence of congestive heart failure symptoms, the patient was treated not only with ACEI and beta-blockers, but also with loop diuretics and aldosterone antagonists. Hydrosaline retention decreased and, in 12 months time, the patient's ejection fraction increased from $25 \%$ to $35 \%$. The exercise capacity still remained excessively low under the circumstances in which the patient had a fear of effort (self-) induced sedentary lifestyle. He was assessed apt to enroll in cardiac rehabilitation programs of physical exercise training and was admitted in our hospital in May 2013.

On May, $16^{\text {th }}, 2013$, his clinical assessment revealed no signs of congestive heart failure, arterial blood pressure$130 / 80 \mathrm{mmHg}$, heart rate- 70 beats/min.

Electrocardiogram: sinus rhythm, Q wave in the inferior leads, and QS pattern in leads V1 and V2; echocardiography: LVEF = $35 \%$, moderate mitral regurgitation.

Laboratory investigations: $\mathrm{Hb}=11.0 \mathrm{~g} / \mathrm{dl}, \mathrm{Ht}=32 \%$, Total Cholesterol= $118 \mathrm{mg} / \mathrm{dl}$, Triglycerides $=87 \mathrm{mg} / \mathrm{dl}$, LDLcholesterol $=76 \mathrm{mg} / \mathrm{dl}$, Creatinine $=1.16$ $\mathrm{mg} / \mathrm{dl}$ (clearance $=53 \mathrm{ml} / \mathrm{min})$, Glycemia $=87$ $\mathrm{mg} / \mathrm{dl}$ (on insuline therapy), Body Mass Index $=27.81 \mathrm{~kg} / \mathrm{m}^{2}$.

The presence of moderate anemia, $11 \mathrm{~g} / \mathrm{dl}$, hemoglobin ferritin levels $=25 \mathrm{ng} / \mathrm{ml}$ 
$($ normal value $=30-400 \mathrm{ng} / \mathrm{ml}) \quad($ recorded siderophylin) was not considered a contraindication for participating in a rehabilitation program.

The levels of NT pro-BNP were 189 $\mathrm{pg} / \mathrm{ml}$, indicating absence of severe heart failure.

The patient agreed to enroll in a physical rehabilitation program and underwent a classic cycle ergometer exercise testing.

His exercise capacity was low (75 J) and the calculated METs amounted to 3.8. The kinesiotherapists deemed that the patient should only undergo minimal physical training activities of low-moderate intensity although his left ventricular systolic performance would have allowed a higher intensity.

The first rehabilitation sessions proved to be very difficult for the patient and in order to elucidate the discrepancy between the slightly decreased systolic performance and the extremely low exercise capacity a cardiopulmonary exercise test was recommended.

The patient's recorded MET units were again 3.8 (peak $\mathrm{VO}_{2} 13.3 \mathrm{ml} / \mathrm{kg} / \mathrm{min}, 1.19$ $\mathrm{L} / \mathrm{min}$ ). He displayed no signs of ventilation kinetics dysfunction. On the contrary, the ventilation threshold was $41 \%$ of the theoretical VO2 max, a marker that is low both in systolic heart failure and in anemia.
But the anaerobic threshold was not in agreement with what we suspected when we conducted the exercise test, namely that his self-imposed sedentary lifestyle had a major contribution to his low exercise capacity, knowing that the VO2 peak is low in case of sedentary lifestyle but the ventilation threshold is normally $70 \%$.

We then raised the question whether anemia had a major contribution, especially as it lowers both the VO2 peak and the ventilation threshold as showed above.

It was determined that the patient had iron deficiency and was treated with iron injections. He was discharged and came back after 2 months. This time his hemoglobin was $13.8 \mathrm{~g} / \mathrm{dl} \quad(\mathrm{Ht}=39 \%)$ and the patient subjectively perceived a significant increase in his exercise capacity. The cardiopulmonary exercise test was repeated and it showed an increase in the VO2 peak to 5.1 METs (17.8 $\mathrm{ml} / \mathrm{kg} / \mathrm{min}, 1.58 \mathrm{~L} / \mathrm{min}$ ) and of the ventilation threshold to $58 \%$, below the normal value of $70 \%$, still a $41.1 \%$ increase as compared with the previous $41 \%$ value (fig 1 ).

The patient was enrolled in moderate intensity rehabilitation programs, which he tolerated well and yielded excellent results after 36 training sessions (initially 17.8 $\mathrm{ml} / \mathrm{kg} / \mathrm{min}$, then $24.5 \mathrm{ml} / \mathrm{kg} / \mathrm{min}$, namely a $37.6 \%$ increase).

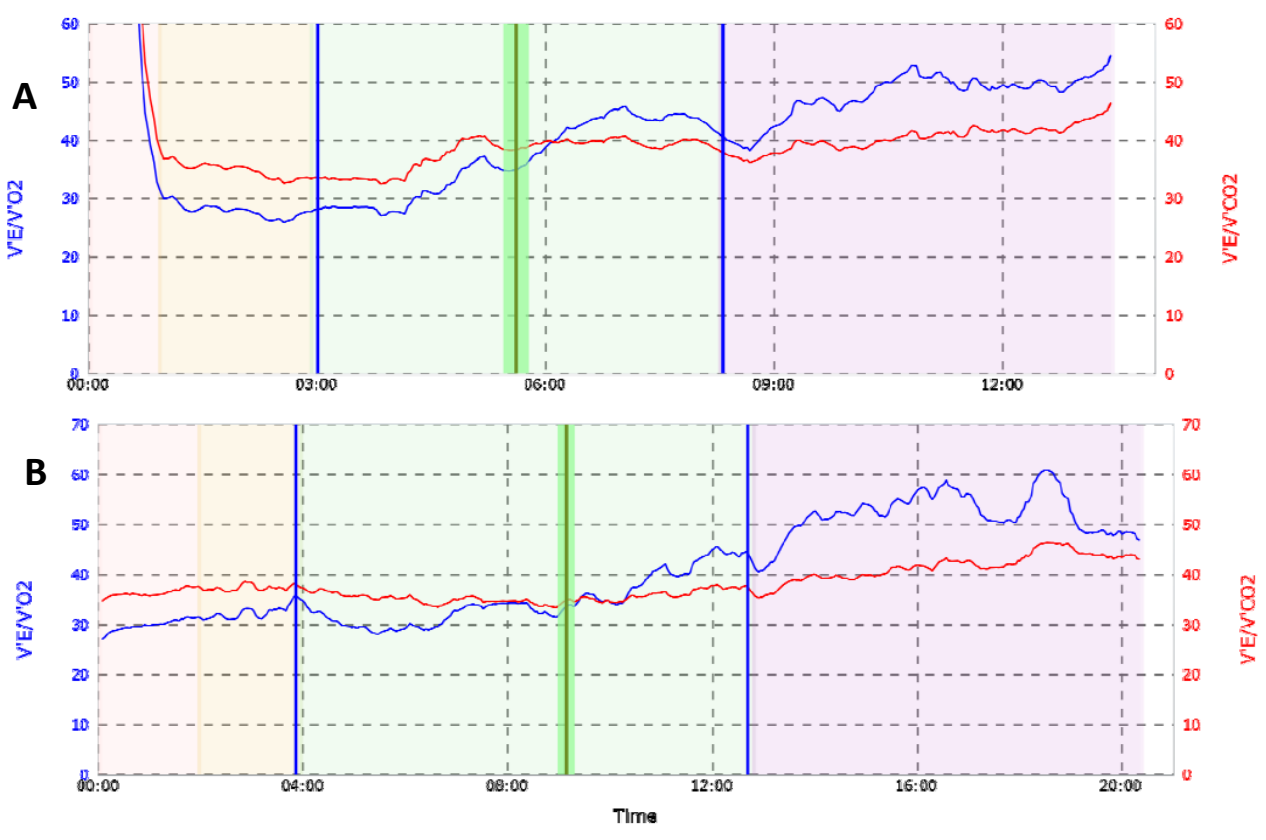


Figure 1. Ventilatory threshold (VT1 $=0.82 \mathrm{~L} / \mathrm{min}, 41 \%$ of the theoretical VO2 max) determined by the ventilatory equivalents method before enrolment in the training program (A) and after 36 training sessions $(1.17 \mathrm{~L} / \mathrm{min}, 58 \%$ of the theoreticalVO2max) (B). VE/VO2, ventilatory equivalent for oxygen; $\mathrm{VE} / \mathrm{VCO} 2$, ventilatory equivalent for $\mathrm{CO} 2$

\section{Discussion}

Nowadays, cardiovascular rehabilitation is a class IA indication not only for patients with ischemic cardiomyopathy, but also for those with heart failure, and our patient was both $(1,7)$.

After completion of phase II cardiac rehabilitation, as a rule consisting of 36 training sessions in 12 weeks, physical activity maintenance is recommended first under supervision (if possible a 6-12 months extended phase II), then without supervision or time limit, home-based rehabilitation representing phase III in the recovery process $(1,8)$.

Taking into consideration the growing number of patients with severe heart failure, most of them will be enrolled in rehabilitation programs after classic exercise tests or even after a 6 minutes' walk test, which might be enough $(1,9)$. In the latter case, there will be no intensive rehabilitation programs, the patients will be only recommended to perform physical activities and walk home $(1,9)$.

Sometimes the pre-rehabilitation assessment methods, of course associated with clinical examination and Doppler tests, are not enough to elucidate the often intricate mechanisms of exercise capacity decrease, as it was the case with our patient (10).

The literature in the field however agrees in recommending the cardiopulmonary exercise testing (CPET) as the best and compulsory method to assess complex cases of patients with poor ischemic or nonischemic systolic performance (10).

\section{Conclusion}

The case illustrates important aspects in the assessment of patients with heart failure previous to their enrolment in rehabilitation
The most important are $\mathrm{VO} 2$ peak, ventilation threshold as well as OUX (Oxygen Uptake Efficiency Slope - OUES) and VE /VCO2 slope, which could be survival predictors for patients with heart failure (10).

In our case, the test confirmed a low VO2 peak without major ventilation anomalies and a low VT, peculiar to both heart failure and anemia, excluding sedentary lifestyle as major cause of low exercise capacity side by side with poor left ventricular systolic performance $(10,11,12)$.

An accurate diagnosis of the pathogenic factors responsible for exercise capacity decrease may lead, like in the case under discussion, to improving and accelerating physical training programs following the identification and treatment of modifiable causes. The outcome will be a faster and more cost efficient recovery, an improved quality of life.

Anemia and iron deficiency in general are known for decreasing exercise capacity in patients with heart failure $(1,13,14)$. It has been demonstrated that iron deficiency by itself, in the absence of anemia (subclinical deficiency), can diminish exercise capacity and the ventilatory threshold $(11,12)$. Consequently, the current tendency to measure iron deposits (ferritin) in patients with heart failure and initiate treatment in case of deficiency (preferably with iron injections) even in the absence of classically defined anemia $(12,14)$.

programs when the causes of decreased exercise capacity are not fully elucidated and there are obvious discrepancies between the 
patients' cardiac performance and their exercise capacity.

\section{Acknowledgement}

This work was supported under the frame of European social fund, Human

\section{References}

1. McMurray JJ, Adamopoulos S, Anker $\mathrm{SD}$, et al; ESC Committee for Practice Guidelines. ESC guidelines for the diagnosis and treatment of acute and chronic heart failure 2012: The Task Force for the Diagnosis and Treatment of Acute and Chronic Heart Failure 2012 of the European Society of Cardiology. Developed in collaboration with the Heart Failure Association (HFA) of the ESC. Eur J Heart Fail. 2012;(8):803-69.

2. Boully C, Hanon O. Heart failure and comorbidities. Geriatr Psychol Neuropsychiatr Vieil. 2015;13(S1):13-22.

3. Lopez A, Cacoub P, Macdougall IC, Peyrin-Biroulet L. Iron deficiency anaemia. Lancet. 2015; pii: S0140-6736(15)60865-0.

4. Nakagawa Y, Yasuno S, Kuwahara K. Differential Relationships Between Anemia and Outcome in Subgroups of Patients With ChronicHeart Failure. Circ J. 2015 ;79(9):1893-4.

5. Piña $\mathrm{IL}$, Lin $\mathrm{L}$, Weinfurt $\mathrm{KP}$, Isitt JJ, Whellan DJ, Schulman KA, Flynn KE; HFACTION Investigators. Hemoglobin, exercise training, and health status in patients with chronic heart failure (from the HF-ACTION randomized controlled trial). Am J Cardiol. 2013;112(7):971-6

6. Wang JS. Anemia, heart failure and exercise training. Int $J$ Cardiol. 2013;168(2):1525-6.

7. Tieh-Cheng F, Shu-Chun H, Chih-Chin H, Chao-Hung W, Jong-Shyan W. Cardiac Rehabilitation in Patients with Heart Failure. Acta Cardiol Sin 2014;30:353 359.
Resources Development Operational Programme 2007-2013, project POSDRU/ 159/1.5/S/138776 titled: "Model colaborativ instituţional pentru translatarea cercetării ştiinţifice biomedicale in practica clinică".

8. Ko JK, McKelvie RS. The role of exercise training for patients with heart failure. Eura Medicophys. 2005; 41(1):3547.

9. Zdrenghea D (sub red.) Recuperare şi prevenţie cardiovasculară. Clusium. 2008

10. Nichols S, Taylor C, Ingle L. A clinician's guide to cardiopulmonary exercise testing 2 : test interpretation. Br J Hosp Med (Lond). 2015 ;76(5):281-9.

11. Callahan LA, Woods KF, Mensah GA, Ramsey LT, Barbeau P, Gutin B. Cardiopulmonary responses to exercise in women with sickle cell anemia. Am $J$ Respir Crit Care Med. 2002;165(9):130916.

12. Bellotto F, Palmisano P, Compostella L, Russo N, Zaccaria M, Guida P, Setzu T, Cati A, Maddalozzo A, Favale S, Iliceto S. Anemia does not preclude increments in cardiac performance during a short period of intensive, exercise-based cardiac rehabilitation. Eur $J$ Cardiovasc Prev Rehabil. 2011;18(2):150-7.

13. Wright SE, Pearce B, Snowden CP, Anderson H, Wallis JP. Cardiopulmonary exercise testing before and after blood transfusion: a prospective clinical study. $\mathrm{Br} J$ Anaesth. 2014;113(1):91-6.

14. Feiner JR, Finlay-Morreale HE, Toy P, Lieberman JA, Viele MK, Hopf HW, Weiskopf RB.High oxygen partial pressure decreases anemia-induced heart rate increase equivalent to transfusion. Anesthesiology. 2011; 115(3):492-8. 